
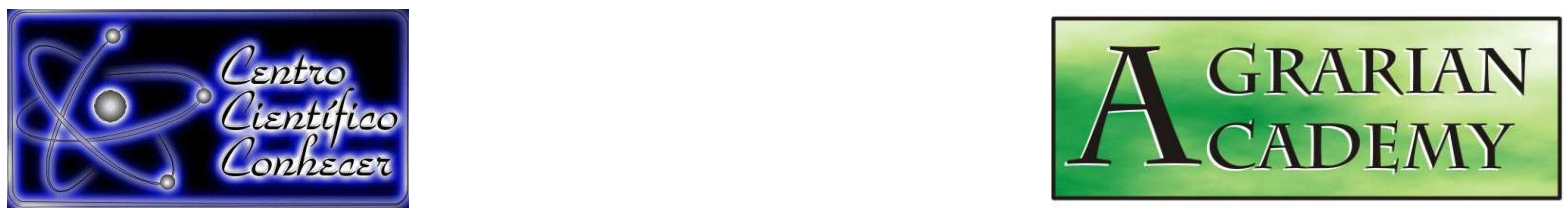

\title{
APLICAÇÕES E IMPLICAÇÕES DA BIOPSIA GUIADA POR ULTRASSOM EM RIM, FÍGADO, BAÇO E PRÓSTATA DE CÃES
}

Tales Dias do Prado ${ }^{1}$, Rejane Guerra Ribeiro ${ }^{2}$, Naída Cristina Borges ${ }^{3}$, Andrigo Barboza de Nardi $^{4}$

${ }^{1}$ Universidade Estadual Paulista, Faculdade de Ciências Agrárias e Veterinárias, Jaboticabal, SP

${ }^{2}$ Universidade Estadual Paulista, Faculdade de Ciências Agrárias e Veterinárias, Jaboticabal, SP

3 Universidade Federal de Goiás, Escola de Veterinária, Goiânia, GO

4 Universidade Estadual Paulista, Faculdade de Ciências Agrárias e Veterinárias, Jaboticabal, SP

Autor correspondente: talesprado@yahoo.com.br

Recebido em: 03/01/2014 - Aprovado em: 04/04/2014 - Publicado em: 12/04/2014

\section{RESUMO}

Com o avanço da Medicina Veterinária, diagnósticos mais precisos e rápidos estão sendo exigidos. A ultrassonografia (US) é um método de diagnóstico por imagem muito utilizado na clínica de pequenos animais. Por meio deste exame é possível detectar alterações nos órgãos que podem sugerir enfermidades como as neoplasias, mas para obtenção de um diagnóstico definitivo recomenda-se a realização de biópsias. A biópsia guiada por ultrassom é uma técnica barata, rápida, dinâmica e com poucos relatos de complicações graves, que permite 0 posicionamento preciso da agulha na região específica que se deseja obter a amostra. O objetivo deste estudo bibliográfico é demonstrar as indicações e implicações da biopsia guiada por US em rim, fígado, baço e próstata de cães, desmistificando algumas situações e chamando atenção para detalhes relevantes, para que assim seja difundido o uso desta técnica na rotina clínica.

PALAVRAS- CHAVE: biopsia, câncer, ultrassom

\section{APPLICATIONS AND IMPLICATIONS OF ULTRASOUND-GUIDED BIOPSY IN KIDNEY, LIVER, SPLEEN AND PROSTATE DOGS}

\begin{abstract}
With the advancement of veterinary medicine, more accurate diagnosis and fast are required. Ultrasound is a diagnostic imaging method widely used in the clinic for small animals. By this test it is possible to detect changes in organs that may suggest diseases such as cancers, but for obtaining a definitive diagnosis is recommended biopsies. The biopsy guida ultrasound is a technique cheap, fast, dynamics and with few serious complications, which allows accurate positioning of the needle in the specific region that is desired to obtain the sample. The objective of this study is to
\end{abstract}


demonstrate the indications and implications of US-guided biopsy in kidney, liver, spleen and prostate dog, demystifying some situations and calling attention to relevant details, so that is widespread use of this technique in clinical practice.

KEYWORDS: Ultrasound, biopsy, cancers

\section{INTRODUÇÃO}

A biopsia de órgãos guiada por ultrassom foi introduzida na Medicina Veterinária há 40 anos (GROMAN et al., 2004), e nos últimos anos esta técnica vem sendo muito requisitada na clínica de pequenos animais, haja vista que através de um posicionamento preciso da agulha é possível um monitoramento contínuo em tempo real (NYLAND \& MATOON, 2005). Além disso, é uma técnica barata, rápida, minimamente invasiva e que geralmente não requer anestesia geral (LIEVE et al., 1999).

Por meio da ultrassonografia (USG) é possível detectar alterações em tamanho, contornos, textura e arquitetura de órgãos abdominais, podendo sugerir uma lesão, mas não permite a diferenciação de lesão benigna ou maligna. Entretanto, a ausência de alterações ultrassonográficas não exclui a existência de doença (CARVALHO, 2004).

Para um diagnóstico definitivo é necessário recorrer às biopsias, que são indicadas para confirmar, sustentar ou eliminar probabilidades diagnósticas. Baseiam-se no histórico do animal, exame físico, laboratoriais, avaliação radiográfica e ultrassonográfica, a fim de obter um prognóstico e planejamento terapêutico (VIGNOLI \& SAUNDERS, 2010).

As complicações relatadas após biopsia guiada por ultrassom no cão incluem hemorragia ou hematoma no local da biópsia, peritonite local ou generalizada, disseminação de células tumorais, pancreatite, hematúria e hidronefrose. Ainda assim, a frequência de complicações graves é muito baixa. As contra-indicações mais importantes para se fazer uma biópsia são os órgãos com tendência hemorrágica e disfunção circulatória grave (NYLAND \& MATTOON, 2005).

No entanto, pode ser difícil obter biopsias sob orientação ultrassonográfica em pacientes obesos ou de massas localizadas profundamente devido à dificuldade de visibilização da lesão. O sucesso de biópsias também depende da habilidade e experiência dos operadores (LIEVE et al., 1999).

Coleta de biopsias orientadas em tomografia computadorizada (TC) são indicadas principalmente para as lesões torácicas e osso ou lesões localizadas em áreas de difícil visibilização com ultrassom, ou seja regiões em que há gás ou osso. Embora a orientação por ressonância magnética (RM) seja possível, os equipamentos são caros, limitando seu uso na rotina clínica. Como consequência, a ultrassonografia é 0 método de escolha na prática veterinária diária devido à grande disponibilidade de equipamentos ultrassonográficos ao menor custo em relação à TC, e ainda por ser portátil, não emitir radiação e realizado em tempo real, permitindo assim pequenos ajustes rápidos durante a biopsia (WINTER et al., 2008).

O objetivo deste estudo bibliográfico é demonstrar as indicações e implicações da biopsia guiada por US em rim, fígado, baço e próstata de cães, desmistificando algumas situações e chamando atenção para detalhes relevantes, para que assim seja difundido o uso desta técnica na rotina clínica. 


\section{REVISÃO DA LITERATURA}

\section{Aspectos gerais da biopsia guiada por ultrassonografia}

Existem dois tipos principais de biopsias: as incisionais e as percutâneas. As biopsias incisionais consistem na remoção cirúrgica de uma porção da lesão ou tecido. São procedimentos altamente invasivos que necessitam de anestesia geral, laparatomia ou toracotomia, para que se colha um fragmento da lesão para a realização de análise histopatológica. As biopsias percutâneas são realizadas com agulhas específicas, introduzidas através da pele, na cavidade abdominal, e que colhem fragmentos para análise histopatológica ou células para análise citológica, sem necessidade de cirurgia (CARVALHO, 2004).

As biopsias percutâneas podem ser guiadas por ultrassom (US), assim aumenta a probabilidade de se obter boas amostras das lesões, pois a agulha será direcionada exatamente para o órgão alterado e, mais precisamente, para a área de lesão detectada ultrassonograficamente. Também evita atingir áreas de tecidos normais, grandes vasos e áreas com conteúdo líquido, que apresentam pouca celularidade ou que podem ser áreas de necrose, minimizar os riscos. Com o auxílio do US também é possível estabelecer a rota mais curta entre o "alvo" e a pele (NYLAND \& MATTON, 2005 ).

\section{Técnicas para guiar biopsias percutâneas por meio de ultrassonografia}

\section{Orientação indireta}

A orientação indireta da agulha refere-se à remoção do transdutor após determinação por US do ângulo e da profundidade de inserção da agulha. A agulha é inserida cegamente após esterilização da pele, e este procedimento deve ser feito rapidamente após a remoção do transdutor para evitar mudanças de alinhamento ou profundidade, causadas pela movimentação do paciente (NYLAND \& MATTON, 2005; VIGNOLI \& SAUNDERS, 2010).

\section{Orientação à mão livre}

A punção à mão livre é realizada segurando o transdutor com uma mão e inserindo a agulha com a outra. A agulha será visibilizada dentro do plano de feixe sonoro, podendo assim ser dirigida para o alvo (LIEVE et al., 1999).

Sistema de orientação para agulha

O sistema de orientação para agulhas utiliza um guia de biopsia acoplado ao transdutor, facilitando a realização da biopsia. Essas guias são como uma cinta rígida, que se prende ao corpo do transdutor e apresenta um apêndice com angulação fixa em relação ao transdutor, no qual as agulhas devem ser encaixadas. Aparelhos mais modernos de ultrassonografia permitem que visibilize no seu monitor uma faixa demarcada por pontos fixos, sendo específica para biopsias realizadas com guias. Quando a agulha é encaixada nessa guia e introduzida através da pele, a imagem da agulha aparece na imagem ultrassonográfica justamente entre os marcadores na tela, o que ajuda a atingir o "alvo" certeiramente (VADEM et al., 2005).

Segundo VIGINOLI \& SAUNDERS (2010) as vantagens deste método são a facilidade de coletar biopsias em lesões pequenas, requerer menos treino e coordenação motora-visual. Como desvantagem, limita as correções de ângulo da 
agulha durante a biopsia, não se conseguindo retirar a agulha rapidamente em caso de movimento brusco do animal e, depois de introduzida a agulha, não se permite a movimentação do transdutor. Este método é pouco utilizado na rotina clínica quando comparado com as biopsias à mão livre.

\section{Tipos de agulhas de biopsias}

Biopsia aspirativa por agulha fina (BAAF)

A biopsia aspirativa por agulha fina geralmente é indicada para massas sólidas pequenas $(<1 \mathrm{~cm})$, lesões císticas, lesões muito vascularizadas ou em suspeita de linfoma ou mastocitoma. Quando o diagnóstico não é conclusivo por meio da BAAF pode-se indicar a biópsia Trucut (NYLAND \& MATTON, 2005). Recomenda-se o uso de agulhas de injeção de 21-25 gauges para BAAF à mão livre, e para biopsia aspirativa guiada, agulha espinhal descartável de nove, de 20 ou de 22 gauges com ponta em bisel (VIGINOLI \& SAUNDERS, 2010).

A BAAF é o método mais utilizado na clínica de pequenos animais, pois é barato, fácil de fazer, e geralmente não precisa de anestesia ou sedação (ROTHUIZEN \& TWEDT, 2009). Segundo NYLAND \& MATTON (2005), não há necessidade de se fazer uma incisão na pele com lâmina de bisturi devido à rigidez dessas agulhas.

\section{Biopsia por fragmento}

A biopsia por fragmento é indicada para grandes massas, doenças difusas ou quando requer uma avaliação histopatológica (VIGNOLI \& SAUNDERS, 2010). Para esse tipo de biopsia são utilizadas agulhas específicas denominadas Trucut. Elas têm tamanhos variados, mas as mais utilizadas são as de calibre 16 a 18 gauges. Essas consistem de uma agulha interna, como um mandril que possui uma reentrância próxima a extremidade afilada, e de uma parte externa, oca, que se acopla perfeitamente (CARVALHO, 2004).

Essas agulhas podem ser encaixadas na "pistola" que quando disparada, faz com que parte interna da agulha vá para a frente e volte para a posição inicial rapidamente, de modo que o fragmento do órgão fique contido na reentrância próxima a extremidade. O fragmento obtido geralmente mede $1,0 \mathrm{~cm}$ de comprimento por 0,2 a $0,3 \mathrm{~cm}$ de espessura (CARVALHO, 2004). Segundo VIGINOLI \& SAUNDERS (2010), uma pequena incisão na pele com lâmina de bisturi número 11 pode ser feita antes da biopsia.

\section{Preparação do paciente}

O paciente deve ser avaliado quanto às desordens hemostáticas antes da realização da biopsia Trucut ou aspirativa, quando há risco significativo de hemorragia. Essa avaliação é realizada a partir do histórico, do exame físico e dos exames laboratoriais, como contagem de plaquetas, tempo de protrombina e tempo de sangramento. Se for diagnosticada coagulopatia, a mesma deve ser tratada antes do procedimento (NYLAND \& MATTON, 2005).

Para a realização do procedimento, solicita-se jejum alimentar de 12 horas, para evitar a sobreposição do fígado pelo estômago e o acúmulo de gases no trato gastrointestinal. $O$ animal é posicionado de um modo que facilite a vizibilização da estrutura a ser abordada pelo ultrassom. Os pêlos da região são tricotomizados e a área preparada assepticamente, antes da introdução da agulha. Na maioria das 
vezes, as biopsias aspirativas podem ser realizadas sem anestesia, salvo em animais inquietos, indóceis ou com dor. Já na biopsia Trucut, é necessária anestesia ou sedação, pois o calibre da agulha é maior (VIGNOLI \& SAUNDERS, 2010).

As complicações da biopsia guiada por ultrassom variam com a experiência do ultrassonografista, do tipo de biopsia, do tamanho da agulha e da natureza da lesão, sendo muito menos comuns do que as técnicas realizadas às cegas. A hemorragia costuma ser secundária e autolimitante. O Doppler colorido auxilia a evitar estruturas vasculares, reduzindo assim as complicações. É possível ocorrer septicemia ou peritonite quando uma amostra de abscesso ou lesão infectada é colhida, mas isso é raro. A semeadura do tumor ao longo do trajeto da agulha é rara com agulhas aspirativas de 22 gauges ou menor, e não deve influenciar na decisão de realizar biopsia (NYLAND \& MATTON, 2005).

\section{Principais órgãos abdominais biopsados}

Os rins, fígado, baço e próstata são sem dúvida, os órgãos abdominais mais biopsados na rotina clínica. Outros órgãos apresentam limitações importantes, como a glândula adrenal, que é muito pequena e vascularizada, medindo em cães de porte médio aproximadamente $20 \mathrm{~mm} \times 10 \mathrm{~mm} \times 10 \mathrm{~mm}$ (CARVALHO, 2004). Já o pâncreas, devido à sua dimensão, limites pouco definidos e localização próxima de estruturas gastrointestinais preenchidas por gás, dificulta sua identificação, bem como sua avaliação ultrassonográfica (MIX \& JONE, 2006). O tamanho do linfonodo abdominal, a distância em relação à superfície da pele e sua proximidade com estruturas vitais, também são preocupações para a realização de biopsia guiada (NYLAND \& MATTOON, 2005).

$\operatorname{Rim}$

IVERSEN \& BRUN (1951) descreveram a primeira biópsia renal (BR) em humano, com o intuito primário de obter maiores informações sobre a morfologia renal, além de comparar os resultados de testes de função renal com o quadro histopatológico correspondente.

De modo geral, é difícil a detecção precoce de uma lesão renal específica em cães e gatos antes que ela cause alterações graves na função do órgão. $O$ aparecimento da doença pode ser insidioso e os sinais clínicos obtidos pela anamnese e exame físico, geralmente não são suficientemente específicos para permitirem o diagnóstico definitivo. Além disso, as anormalidades funcionais observadas por métodos laboratoriais são similares em diferentes tipos de desordens renais, fazendo-se necessária a avaliação morfológica do rim (BARTGES \& OSBORNE, 1995).

A BR também avalia a resposta ao tratamento e verifica a progressão e reversibilidade da doença renal. A distinção entre insuficiência renal reversível e irreversível, baseada em achados clínicos, geralmente é difícil, uma vez que os sinais não são específicos o bastante para o estabelecimento do diagnóstico definitivo. A maioria dos testes de função renal indicam a competência funcional dos rins no momento em que são realizados, não sendo evidência de duração, tipo de lesão ou melhora do quadro. A avaliação histopatológica do tecido renal, obtido por técnicas de biopsia, pode indicar a reversibilidade ou irreversibilidade da doença, distribuição (focal ou generalizada) e evolução da lesão (aguda ou crônica) (AMORIM et al., 2005).

Outra vantagem oferecida pela técnica é a possibilidade de submissão do 
tecido renal ao cultivo bacteriológico, permitindo a determinação do agente específico responsável pelos quadros de nefrite bacteriana (MELCHERT et al., 2010).

Segundo VADEN et al. (2005), as indicações para a realização de biópsia renal são: proteinúria, suspeita de necrose tubular aguda, síndrome nefrótica, hematúria, doença sistêmica com suspeita de envolvimento renal ou clínica de lesão renal, falência renal aguda de causa desconhecida, aumento sérico da creatinina, doença túbulo-intersticial, diabetes, amiloidose, hipertensão.

A agulha de BR pode ser introduzida no órgão livremente (à mão livre) ou com guia acoplado ao transdutor, o que assegura o plano de incidência da agulha, mas atrapalha a manipulação, sendo mais útil para biopsias de massas focais (NYLAND \& MATTOON, 2005). Como esses guias são específicos a determinadas probes, necessitam de software computadorizado para a operação, aumentando assim o custo do procedimento (VADEN et al., 2005).

É indicado o uso de agulhas de 16 ou 18 gauges para a realização da técnica, pois com agulhas de 14 gauges há uma penetração mais profunda do parênquima, podendo atingir a medula renal, aumentando assim as chances de hemorragia. Como a hemorragia é a principal complicação da BR, deve-se evitar o procedimento em animais com anemia grave e coagulopatias. Também deve-se considerar que pacientes com doença renal podem apresentar alterações como azotemia e hipertensão sistêmica, aumentando os riscos de hemorragia. Porém, essas alterações não contra-indicam a realização deste procedimento, mas exige acirrada monitorização do paciente (VADEN et al., 2005).

O pólo caudal do rim esquerdo é o local preferido para biopsia Trucut quando há suspeita de doença renal difusa. Na maioria das vezes, recomenda-se a colheita de duas a três amostras para assegurar uma amostragem adequada (NYLAND \& MATOON, 2005), pois a BR é considerada de boa qualidade quando o número de glomérulos for suficiente para representar todo parênquima renal. Apesar de não existir um padrão estabelecido na veterinária, é indicado em várias literaturas que o número mínimo de glomérulos por amostra deve ser cinco (ZATELLI et al., 2005; MELCHERT et al., 2010).

A amostragem do córtex dos pólos cranial ou caudal de ambos os rins pode ser obtida através do abdome ventral, na região mesogástrica, mas deve-se evitar a região do hilo, devido a proximidade da pelve e dos grandes vasos sanguíneos. A posição da agulha durante a BR guiada é melhor visibilizada no plano sagital. A biopsia do rim direito é menos recomendada devido a sua localização cranial e a proximidade com o pâncreas (MELCHERT et al., 2010).

Estudo realizado por (MELCHERT et al., 2010) com 43 cães sem raça definida, adultos, hígidos e peso corporal entre oito e $20 \mathrm{~kg}$ demonstrou a eficácia, segurança e o valor de diagnóstico da técnica de BR guiada por ultrassom, usando agulhas semiautomáticas de 16 gauges.

A baixa incidência de complicações pode estar associada ao calibre da agulha, e por ser semiautomática, diminui a probabilidade de penetração da agulha na pelve renal, minimizando o traumatismo ao órgão e diminuindo a incidência de hemorragias, que é a principal complicação após a realização de BR (MELCHERT et al., 2010).

AMORIM et al. (2005) no estudo feito com 86 cães, compararam os resultados obtidos na BR com o exame pós mortem, e observaram a concordância de diagnóstico de 95\%, reafirmando outros trabalhos realizados em Medicina Veterinária de alta correlação entre os diagnósticos (nunca menor que 90\%). 
Uma única amostra de biópsia pode não ser representativa de doença se as lesões não forem distribuídas de maneira uniforme. Mas existe uma preocupação que uma série de biopsias poderia induzir lesões parenquimatosa ou vascular, o que dificultaria a diferenciação da doença renal progressiva. Diante disto, GROMAN et al. (2004) realizaram um estudo com 10 cães, os quais foram submetidos a BR com dois, quatro e seis meses de idade, colhendo quatro fragmentos por vez, com finalidade de avaliar os efeitos estruturais e funcionais de uma série de BR guiada por ultrassom, obtidas com agulhas de 18 gauges. Concluíram por meio de exames de cintilografia e exames pos mortem, que as lesões iatrogênicas não têm como ser confundidas com lesões progressivas, e que estas mesmas lesões não causaram nenhum dano funcional aos rins.

\section{Fígado}

O exame ultrassonográfico, a biópsia hepática e o exame histopatológico são de suma importância na avaliação de um paciente com doença hepática. No entanto, uma biópsia do fígado avalia apenas uma pequena porcentagem do fígado e não o fígado inteiro. Consequentemente, esses resultados devem ser sempre combinados com as informações clínicas e dados laboratoriais (ROTHUIZEN \& TWEDT, 2010).

A detecção, no parênquima hepático, de lesões compatíveis com neoplasias é a aplicação diagnóstica mais importante da ultrassonografia hepatobiliar. $\mathrm{O}$ aspecto ultrassonográfico do parênquima hepático do cão é uniforme, com um nível médio de ecogenicidade. Somente as veias portas e as veias hepáticas interrompem a arquitetura uniforme do parênquima. A ecogenicidade do fígado normalmente é semelhante à do córtex renal, ou o fígado é ligeiramente mais hiperecóico. O baço apresenta uma intensidade de ecogenicidade bem maior que aquela do parênquima hepático. A vesícula biliar é geralmente anecóica, oval, localizada justamente na linha média direita (NYLAND \& MATTON, 2005).

BARR (1992) realizou um estudo de mensuração hepática na tentativa de padronizar o volume hepático em cães. Todavia, ainda há grande discordância sobre a eficácia desse método de mensuração. Devido a isso, a determinação do tamanho hepático no cão normalmente é baseada no método subjetivo, e as diferenças de raça e de conformação corpórea, devem ser consideradas quanto a interpretação.

Suspeita-se de hepatomegalia quando ocorre aumento na distância entre o diafragma e o estômago, extensão do lobo hepático para a porção ventral da cavidade abdominal e visualização das margens hepáticas arredondadas. A suspeita de fígado reduzido de tamanho é decorrente de pobre visibilização do parênquima, diminuição da distância entre o diafragma e o estômago e menor extensão do parênquima na porção ventral da cavidade abdominal (FROES, 2004).

A aparência ultrassonográfica da neoplasia é determinada pela homogeneidade de seu tipo celular, pela quantidade de vascularização, pela extensão da hemorragia ou necrose, pela presença de tecido fibroso e pela deposição de minerais (NYLAND \& MATTON, 2005).

Os tumores hepáticos primários e secundários apresentam manifestações ultrassonográficas amplamente variáveis, incluindo o padrão normal. Essas variações de configurações lesionais ocorrem tanto entre diferentes tipos de tumores quanto entre os iguais. Tumores histologicamente diferentes podem apresentar imagens semelhantes. Apesar dessa sobreposição de achados, e embora a biópsia seja imprescindível para o diagnóstico definitivo do tipo neoplásico, a ultrassonografia pode sugerir lesões tumorais (FROES, 2004). 
Conforme estudo realizado por GUILLOT et al. (2009) com 70 cães, o exame ultrassonográfico é de grande valia para sugerir hepatopatias e principalmente neoplasias hepáticas, mas nenhum sinal USG é patognomônico de doença hepática específica, quando comparado com os exames citológicos. Também não foram observados sinais ultrassonográficos preditivos de inflamação hepática.

A relação risco-benefício da biopsia hepática deve ser analisada em cada situação; apesar da chance de complicações graves ocorrerem ser baixa, sempre há riscos. A experiência do ultrassonografista tem também uma influência significativa sobre a taxa de complicações. No entanto, a maioria das doenças do fígado são melhores diagnosticadas e tratadas mediante a biópsia hepática (ROTHUIZEN \& TWEDT, 2010).

Para realizar a biopsia hepática o animal deve estar em jejum de aproximadamente 12 horas, para garantir o esvaziamento do estômago, para que não cubra a superfície visceral caudal do fígado, e devido à necessidade de anestesia ou sedação em casos de biopsia por fragmento (ROTHUIZEN \& TWEDT, 2010).

Como o fígado produz todos os fatores de coagulação, exceto Fator VIII, o sangramento pode ser uma das complicações de biopsia hepática. A quantidade média normal de perda de sangue em uma biópsia de fígado é de cerca de $2 \mathrm{~mL}$ em cães normais (VASANJEE et al., 2006).

A avaliação dos fatores de coagulação é indicada antes da realização de biopsias, pois se os testes estiverem normais torna-se uma preocupação a menos. A capacidade de reserva do fígado na produção de fatores de coagulação é tão grande que na maioria das doenças hepáticas, raramente esses fatores estão diminuídos ao ponto de se tornarem um fator limitante. Evidências clínicas de sangramento ou alterações acentuadas nos testes de coagulação, como trombocitopenia (plaquetas $<80.000$ ) ou prolongamento do tempo de coagulação aumentam o risco de sangramento após uma biópsia do fígado (BIGGE et al., 2001).

O ideal é que antes da realização de uma biópsia hepática sejam avaliados a tromboplastina parcial ativada (TPA), o tempo de protrombina (TP), o fibrinogênio, as plaquetas e o tempo de sangramento da mucosa oral (TSMO). Quando a concentração de fibrinogênio é inferior a $50 \%$ do valor de referência, é contra-indicada a biopsia hepática (ROTHUIZEN \& TWEDT, 2010).

$\mathrm{Na}$ obstrução prolongada ou completa do fluxo da bile, a absorção intestinal de vitaminas lipossolúveis $\mathrm{K} 1$ pode ser severamente prejudicada, devido à falta de ácidos biliares que entram no intestino. Nestes casos, é indicado administrar vitamina $\mathrm{K} 1$ (1-5 mg/kg por via subcutânea diariamente durante vários dias) e, em seguida, reavaliar os tempos de coagulação, antes da biópsia. Alguns pesquisadores recomendam a administração da vitamina $\mathrm{K} 1$ a todos os pacientes se os tempos de coagulação se apresentarem anormais. No entanto, se não houver deficiência de vitamina K, provavelmente haverá pouca melhoria (BIGGE et al., 2001).

Se houver anormalidades no TP, TPA, ou TSMO deve-se administrar plasma fresco duas horas antes do procedimento e o paciente deve ser monitorado durante e após a biopsia. Se o sangramento persistir de meia a uma hora após a biopsia, pode ocasionar risco de morte ao animal, podendo ser tratada com a administração de plasma ou sangue total fresco, e em último caso deve-se recorrer a cirurgia para conter a hemorragia (BIGGE et al., 2001)

Uma outra complicação de biopsia hepática é a indução de choque vagotônico imediatamente após o procedimento. Biopsias com pistola automática 
produzem um impulso muito grande no fígado, o que pode provocar uma reação de choque fatal em gatos, mas isto não é relatado em cães. Os dutos biliares e a vesícula biliar possuem uma densa inervação autônoma. O trauma induzido pela penetração com uma agulha larga de biópsia, também podem induzir a uma reação autônoma, com bradicardia e choque profundo dentro de 30 minutos de procedimento (ROTHUIZEN \& TWEDT, 2010).

Considera-se uma biopsia hepática "ideal" quando o tamanho do fragmento colhido é satisfatório e extraído da área lesada. Na doença hepática difusa, a biópsia provavelmente representará o fígado inteiro, mas na doença focal ou regional tornam-se mais problemáticas, sendo essencial o auxílio da US, para direcionar a biopsia para a região em questão (ROTHUIZEN, 1999).

O ideal é que fossem feitas de duas a três biopsias de cada lobo hepático, visto que as áreas aparentemente normais ultrassonograficamente também podem estar lesadas (ROTHUIZEN, 1999).

A biopsia aspirativa com agulha fina (BAAF) e o exame citológico são os mais realizados em pequenos animais com doença hepática. Complicações hemorrágicas são incomuns, não necessitando de realização prévia de testes de coagulação. No entanto, existem limitações a BAAF e exame da citologia hepática. Nesses incluem a falha de identificar corretamente a doença primária devido ao pequeno tamanho da amostra e a citologia não refletir a morfologia da arquitetura parenquimatosa (VIGNOLI \& SAUNDERS, 2010).

A maioria dos casos de BAAF são realizados utilizando uma agulha de 20 ou 22 gauges. O tecido é aspirado em um procedimento idêntico ao utilizado para as estruturas periféricas, como os gânglios linfáticos. A agulha acoplada a uma seringa de 5 ou $12 \mathrm{~mL}$ é introduzida sob a orientação do US no fígado. No local da aspiração, a agulha é avançada e retirada rapidamente de 0,5 a $1 \mathrm{~cm}$ por diversas vezes. As células dentro da agulha são encaminhadas para o exame citológico. Outros preferem aplicar pressão negativa sobre o êmbolo da seringa enquanto aspira o fígado. Essa técnica permite colher mais células, mas também resulta em contaminação com sangue (ROTHUIZEN \& TWEDT, 2010).

A biopsia hepática com agulha Trucut, geralmente requer uma maior experiência do ultrassonografista e preparo do animal, sendo mais conclusiva, pois se obtém um fragmento maior e é feito exame histopatológico. Uma das vantagens da pistola de Trucut é que opera-se com tanta rapidez, que um fígado fibrótico é mais facilmente amostrado. Nessas situações, o fígado pode ser difícil de punção com agulhas convencionais. Como regra, a maioria das Trucut semi-automáticas e pistolas devem ser disparadas dois centímetros antes de chegar no fígado e por isso é importante observar se não tem nenhuma estrutura antes (ROTHUIZEN \& TWEDT, 2010).

Vários estudos comparam a BAAF e a biopsia Trucut, e em todos podem ser observados um resultado mais fidedigno no exame histopatológico feito com agulha Trucut quando comparado com a citologia feita por BAAF. Estudo realizado por WANG et al. (2004) com 97 cães e gatos compararam a citotogia aspirativa com o exame histopatológico do fígado e concluíram que apenas $30 \%$ dos casos caninos e $51 \%$ dos casos felinos apresentavam uma relação de compatibilidade nos exames citológicos e histopatológico. Nesse estudo, o diagnóstico de hepatopatia vacuolar foi 0 que apresentou um maior percentual de concordância, enquanto doença inflamatória foi diagnosticado corretamente em apenas $25 \%$ dos cães e gatos.

Embora a BAAF seja muito utilizada pelos clínicos no diagnóstico de 
lipidose hepática em felinos, foi relatado por WILLARD (1999) quatro casos de gatos diagnosticados com lipidose hepática por BAAF erroneamente, pois se tratava de linfomas.

\section{Baço}

As funções básicas do baço são: hematopoiese (com o estímulo adequado), fagocitose, imunorregulação, resposta à estimulação antigênica, metabolismo do ferro e armazenamento de sangue (BICHARD \& SHERDING, 1998).

Os distúrbios esplênicos podem ser separados em duas categorias, as esplenomegalias localizadas que incluem as neoplasias primárias ou metastáticas, a hiperplasia nodular, hematoma e abscesso, e as esplenomegalias generalizadas que podem resultar de doenças inflamatórias ou infecciosas, esplenonegalia hiperplásica ou congestiva e doenças infiltrativas (BICHARD \& SHERDING, 1998).

Por meio da ultrassonografia é possível avaliar o tamanho e o parênquima esplênico, detectando a presença de lesões difusas ou focais, sólidas ou cavitárias. O US também pode guiar as biopsias aspirativas ou Trucut, facilitando a obtenção de amostragem de lesões focais ou auxiliando a determinar a causa de esplenomegalia difusa (NYLAND \& MATTON, 2005).

Sem dúvida, as biopsias aspirativas de baço são mais indicadas que as Trucut, devido ao risco de hemorragias tanto nos humanos quanto nos animais (CHRISTOPHER, 2003). NYLAND \& MATTON (2005) indicaram para a realização da BAAF o método indireto ou à mão livre, utilizando agulhas de 20 a 22 gauges. Já LEBLANC et al. (2009) indicaram agulhas de 22 a 25 gauges.

Em lesões focais menores, o uso de um guia de biópsia e de uma agulha espinhal contribuem para um posicionamento preciso da agulha. E em lesões de massas esplênicas sólidas, as biopsias Trucut são úteis e podem ser realizadas com segurança, quando o aspirado não for conclusivo (NYLAND \& MATTON, 2005).

Os clínicos manifestam muitas preocupações com as possíveis complicações da aspiração do baço, especialmente a hemorragia. Mas essas complicações também dependem do tamanho e número de amostras obtidas, da probabilidade de dano aos vasos, da natureza da patologia, bem como da localização da lesão. No entanto, não há evidências que o sangramento seja tão importante ao ponto de limitar a técnica por complicações em cães, gatos ou seres humanos (CHRISTOPHER, 2003). SODERSTROM (1979) aspirou mais de 1000 baços humanos com agulhas de 22 gauges ou com menor diâmetro, porém não observou nenhuma complicação hemorrágica. Segundo CHOU et al. (2008), a incidência de hemorragia esplênica pós biopsia está entre $0 \%$ e $2 \%$. CHRISTOPHER (2003) também relatou que em BAAF realizadas em 28 cães e cinco gatos não observou nenhum tipo de complicação.

Sempre é recomendado avaliar os parâmetros de coagulação antes da realização de qualquer tipo de biopsia esplênica, pois a biopsia ou aspirado de baço geralmente são indicados em animais com doenças hematológicas, que muitas vezes estão associadas à trombocitopenia. Além disso, embora haja um risco teórico de semear células tumorais ou propagação de organismos com aspiração por agulha fina, não há nenhuma evidência de que isso resultou da aspiração do baço nos animais (CHRISTOPHER, 2003).

Existem duas técnicas para obtenção de amostras citológicas: a punção aspirativa, que é a mais difundida e a punção não aspirativa (LEBLANC et al., 2009). Já ZAJDELA et al. (1987) descreveram pela primeira vez o uso da técnica não aspirativa em humanos, para obtenção de amostras citológicas de tumores 
mamários. Os autores observaram que a técnica sem aspiração causou menos trauma no tumor e nos tecidos ao redor, diminuindo a quantidade de contaminação das amostras com sangue, permitindo assim uma avaliação mais sensível.

Em cães, a técnica para aquisição de amostras com agulha fina sem aspiração guiada por US em vários tecidos, foi descrita pela primeira vez em 1995. Desde então, defendem a técnica como um meio de obtenção de amostras com menos hemodiluição e maior celularidade (MENARD \& PAPAGEORGES, 1995).

Para realização BAAF de baço, utiliza-se agulha de 22 a 25 gauges e seringas que são usadas para aplicar vácuo e obter pressão negativa para a colheita das células. Já a biopsia com agulha fina sem aspiração, não necessita de seringa e a sucção não é aplicada. Nesta técnica também se utiliza uma agulha de 22 a 25 gauges, que é guiada pelo ultrassom para o órgão alvo e introduzida e redirecionada várias vezes, na tentativa de deslocar células para o interior da agulha (LEBLANC et al., 2009).

LEBLANC et al. (2009), realizaram o primeiro estudo comparando a qualidade das amostras citológicas de baço obtidas pela técnica de aspiração e não aspiração. A comparação das duas técnicas foi baseada na celularidade global, quantidade de sangue e preservação da morfologia celular nas amostras citológicas. Concluíram então, que com a técnica sem aspiração de baço, obtém-se amostras citológicas menos hemodiluídas e com mais celularidade comparando com a técnica aspirativa.

Estudo realizado por LIEVE et al. (1999) avaliou a precisão da técnica de biopsia guiada por US e a qualidade das amostras histopatológicas de baço obtidas com agulhas reutilizadas e reesterilizada. Observaram que embora $90 \%$ das biópsias de baço contivessem tecido esplênico, o valor diagnóstico das amostras foi inadequado, devido ao pequeno tamanho e baixa qualidade dos espécimes. Todas as amostras também apresentavam arestas de cortes afiadas, mesmo com a reutilização de agulhas.

Sem dúvida, a punção aspirativa ou não aspirativa por agulha fina são os métodos mais indicados para evitar danos ao tecido e hemorragia. No entanto, limita a diferenciação das neoplasias esplênicas, sendo indicado nestes casos o exame histopatológico (LIEVE et al., 1999).

\section{Próstata}

No campo da patologia comparada, pesquisas envolvendo a próstata canina vêm, nos últimos anos, despertando crescente interesse da comunidade científica mundial. Isso, em parte, pode ser atribuído ao fato dessa glândula apresentar, sob vários aspectos, semelhanças morfológicas e funcionais com a próstata humana e, por conseguinte, pela possibilidade de vir a se constituir em um modelo experimental para estudo das alterações prostáticas no homem (SANTANA, 2006). Em cães, doenças de próstata são comuns em qualquer raça, sendo observadas com maior frequência naqueles com mais de seis anos de idade (AMORIN et al., 2002).

As afecções prostáticas mais prevalentes nos cães incluem hiperplasia prostática benigna, prostatite bacteriana, abscesso prostático, cistos prostáticos e as neoplasias (JOHNSTON et al., 2000; WHITE, 2000).

A história clinica fornece informações relevantes que auxiliam no diagnóstico. Animais que apresentam sinais clínicos relacionados com disúria, hematúria, polaciúria, tenesmo, constipação, dor abdominal, sangramento peniano, devem ter como diagnóstico diferencial as afecções da próstata. Além disso, é 
fundamental a palpação retal na avaliação da glândula. Características como tamanho, consistência, mobilidade, sensibilidade dolorosa e simetria devem ser cuidadosamente avaliadas. Porém, frequentemente são necessários exames complementares para determinar o tipo e gravidade da lesão (JOHNSTON et al., 2000; WHITE, 2000; HEDLUND, 2002).

Os exames radiográficos, ultrassonográficos, microbiológico do sêmen, citológico e histopatológico contribuem na diferenciação das afecções da glândula, além das dosagens de fosfatase ácida prostática (PAP) e antígeno prostático específico (PSA) (HENDLUND, 2002; AMORIM et al., 2005).

A partir da década de 1980, o diagnóstico por imagem da glândula prostática, foi fortemente impulsionado com o advento do exame ultrassonográfico bidimensional, sendo este um método seguro, não invasivo e que permite a avaliação do contorno, simetria, posicionamento e, principalmente, da ecotextura glandular (SOUZA \& TONIOLLO, 1999). Além disso, esse procedimento tem-se revelado mais eficiente do que o exame radiográfico para avaliação do parênquima e do tamanho prostático (ATALAN et al. 1999). O exame ultrassonográfico da glândula prostática pode ser realizado pelas vias retal ou transabdominal. A abordagem retal tem a vantagem de permitir que a imagem seja obtida mesmo quando a próstata está situada em uma posição intrapélvica, porém o alto custo dos transdutores retais e a necessidade de realização de enemas e anestesia dos animais têm impedido seu uso. Na maior parte das vezes, a abordagem transabdominal é satisfatória (THIBAUT et al., 2009).

Já no homem, a biopsia transretal foi descrita pela primeira vez em 1987, e desde então é o principal método de diagnóstico de câncer de próstata. Embora seguro e amplamente utilizado, o procedimento pode apresentar complicações, como sangramento, principalmente porque atualmente está preconizado colheita de pelo menos 12 fragmentos prostáticos (BACKHAUS et al., 2007).

BASTOS et al. (2008) avaliaram 387 biopsias prostáticas transretal humanas guiadas por US e, frente as complicações hemorrágicas, utilizaram um balão de compressão com sonda retal número 28 e dois preservativos fixados por anéis elásticos, a cerca de 10 e $15 \mathrm{~cm}$ da sua extremidade distal. A sonda foi conectada a uma pêra de esfigmomanômetro para a insuflação controlada do compartimento distal do preservativo, formando um balão moldável à anatomia local.

O efeito compressivo foi mantido por 15 minutos e o posicionamento do balão de compressão observado por USG, pois o ideal é que o balão promova compressão da próstata contra a sínfise púbica. Dos 387 casos foram constatados 15 sangramentos, dos quais 14 apresentaram parada com a utilização do balão, e apenas um caso houve persistência do sangramento após o uso do balão.

No cão, a próstata normal apresenta contorno liso e razoavelmente bem circunscrito. Ao exame ultrassonográfico, a próstata normal de um cão jovem ou de meia idade não castrado, tem padrão parenquimal razoavelmente homogêneo com textura média a fina. A ecogenicidade varia de hiperecóica a hipoecóica, embora a ecogenicidade moderada seja mais comum. Geralmente, o formato bilobado da próstata pode ser reconhecido na imagem em plano transversal, e esse seria suavemente margeado; uma fina margem hiperecóica representando a cápsula pode ser visibilizada. A uretra prostática pode ser visibilizada e aparece como uma estrutura circular, hipoecóica a anecóica, na linha central, dentro da porção central, dorsal ou ventral à glândula. A próstata é circular ou oval nas imagens sagitais (NYLAND \& MATTON, 2005).

O aspecto das anormalidades prostáticas pode ser dividido em lesões 
parenquimatosas focais e difusas e anormalidades paraprostáticas. As lesões focais mais comumente identificadas no exame ultrassonográfico da próstata são cistos intraprostáticos, pequenos (menos de um $\mathrm{cm}$ de diâmetro), com parede lisa, bem definida e com conteúdo líquido anecóico. Abscessos ou tumores prostáticos com um componente cístico podem ter aspecto ultrassonográfico idêntico, de maneira que para um diagnóstico definitivo é necessária a aspiração com agulha e citologia (CARVALHO, 2004).

O exame ultrassonográfico da próstata é feito com transdutores de $5 \mathrm{MHz}$, mas quando é necessária uma visibilização mais detalhada recomendam-se transdutores de 7,5 ou $10 \mathrm{MHz}$. Esse exame tem sido realizado com sucesso como guia para obtenção de amostras de biopsia, bem como a estabelecer um diagnóstico preliminar das prostatopatias. As amostras por BAAF ou biopsia Trucut geralmente são obtidas na região caudo-ventral do abdome, lateral ao prepúcio (GADELHA et al., 2009).

Como o prênquima prostático é mais ecogênico que os outros órgãos abdominais, deve-se sacudir ou movimentar o mandril da agulha para facilitar sua visibilização durante as biopsias aspirativas. Agulhas revestidas de teflon melhoram a visibilização, mas são mais caras e raramente necessárias (NYLAND \& MATTON, 2005).

A biopsia Trucut pode ser realizada com pistola automática e agulha de 18 gauges ou de forma manual com agulha de 14 gauges. Geralmente, após esse procedimento, o animal apresenta hematúria, e menos comum edema escrotal. É contra-indicada em casos de prostatite aguda e abscessos prostáticos, pois pode desenvolver uma peritonite séptica, sendo recomendado nesses casos a biopsia aspirativa, tendo o cuidado de manter a agulha em pressão negativa durante 0 procedimento (NYLAND \& MATTON, 2005).

A citologia realizada com as amostras obtidas por BAAF da próstata tem mais vantagens quando comparada com as amostras do fluído prostático, pois as células escamosas no aspirado revelam metaplasia escamosa, enquanto no fluido prostático as mesmas células são consideradas normais (GADELHA et al., 2009).

Estudo realizado por POWE et al. (2004) demonstraram concordância entre os resultados citológicos e histopatológicos da próstata canina, em que $80 \%$ dos casos, ou seja, 20 das 25 análises coincidiram com o mesmo diagnóstico.

\section{CONSIDERAÇÕES FINAIS}

Com o avanço da Medicina Veterinária, diagnósticos mais precisos e rápidos estão sendo exigidos. A USG é um exame barato, rápido, indolor e não invasivo que auxilia a detectar alterações no tamanho, formato, textura e arquitetura dos órgãos abdominais, sugerindo diversas enfermidades.

Muitas dessas enfermidades, principalmente as neoplasias, só tem um diagnóstico definitivo mediante exames citológicos ou histopatológicos, realizados por biopsias.

A biopsia guiada por ultrassom, graças à modernização dos equipamentos ultrassonográficos, vem se tornando uma rotina na clinica médica. Pois por meio destes, se consegue posicionar a agulha de forma precisa na lesão específica ou órgão em que se deseja obter fragmentos ou células para realização de exames, com monitoramento contínuo em tempo real.

Ainda observa-se insegurança de vários clínicos e ultrassonografistas em indicar a biopsia guiada, frente à possibilidade de complicações, tais como 
hemorragia, disseminação de células tumorais e peritonite. Nesta revisão de literatura observou-se que complicações realmente podem acontecer, mas em número bastante reduzido, e que na grande maioria das vezes passíveis de resolução, o que não limita o uso desta técnica, visto o seu grande poder de diagnóstico.

\section{REFERÊNCIAS}

AMORIM, R.L.; BANDARRA, E.P.; MOURA, V.M.B.D.; DI SANTIS, G.W. Aspectos histopatológicos da hiperplasia prostática benigna em cães. Revista brasileira de ciências veterinárias, Niterói, v.11, n.1/2, p.63-27, 2002.

AMORIM, R.L.; DI SANTES, G.W.; MOURA, V.M.B.D.; BANDARRA, E.P. Correlação diagnóstica entre biopsia "de janela" e exame pos mortem em rins de cães. ARS Veterinária, Jaboticabal, v. 21, n. 1, p. 86-90, 2005.

ATALAN, G.; HOLT,P.E.; BARR , F.J. Ultrassonography estimation of prostate size in normal dogs and relationship to bodyweight and age. Journal of Small Animal Practice, v. 40, p.119-122,1999.

BACKHAUS, R.M.; TASSIERRA, V.M.; GUZMAN, A.S.; OLIVA, D.F.; TORMO, B.F.; CRUZ, J.J.F. Estrategias para la biopsia de próstata. Revisión de la literatura. Actas Urology Espanish, Valencia, v. 31, n. 10, p. 1089-1099, 2007.

BARR, F. Ultrassonographic assessment of of liver size in the dogs. Journal of Small Practice, Oxford, v. 33, n. 4, p. 359-364, 1992.

BARTGES, J.W., OSBORNE, C.A. Canine and feline renal biopsy. In: OSBORNE, C.A., FINCO, D.R. Canine and feline nephrology and urology. Baltimore: Lea e Febiger, p. 277-302.1995.

BASTOS, R.M.; MACHADO, A.L.; CAPPUCCI, A.; FATIO, M.; MATSUMOTO, C.A.; TESTAGROSSA, L.A.; CASTELLO, R.; GUIDO, M.G.C. Biopsia de próstat guiada por ultrassonografia: Como minimizar complicações hemorrágicas. Actas Urológica, São Paulo, v. 25, n. 2, p. 41-46, 2008.

BICHARD, S.J.; SHERDING, R.G. Manual Saunders Clínica Médica de Pequenos Animais. 1. Ed. São Paulo: Roca, p. 201-209.1998.

BIGGE, L.A., BROWN, D.J., PENNINCK, D.G. Correlation between coagulation prolife findings and bleeding complications after ultrasound-guided biopsies: 434 cases (1993-1996). Journal American Hospital Association, v. 37, n.3, p. 228233, 2001.

CARVALHO, F.C. Ultrassonografia intervencionista. In: KANAYAMA, L.M. Ultrassonografia em pequenos animais. 1 ed. São Paulo: Roca, p. 347-356.2004.

CHOU, Y.H.; CHIOU, H.J.; TIU, C.M.; CHIOU, S.Y.; WANG, H.K. Ultrasonographyguided percutâneos interventions procedures of the spleen. Journal Medicine Ultrasound, Philadelphia, v. 16, n. 4, p. 249-255, 2008. 
CHRISTOPHER, M.M. Cytology of spleen. Veterinary Clinical North American Small Animal, v. 33, p. 135-152, 2003.

FROES, T.R. Utilização da ultrassonografia em cães com suspeita de neoplasias do sistema digestório (fígado, intestino e pâncreas). 2004. 148 f. Tese (Doutorado em Medicina Veterinária). Faculdade de Medicina Veterinária e Zootecnia, Universidade de São Paulo, São Paulo.

GADELHA, C.R.F.; VICENTE, W.R.R.; RIBEIRO, A.P.C.; MACHADO, L.D.S. Ultrassonografia, citologia e exame microbiológico da próstata de cães em diferentes idades. Arquivo Brasileiro de Medicina Veterinária e Zootecnia, Belo Horizonte, v. 61, n. 6, 2009.

GROMAN, R.P.; BAHR, A.; BERRIDGE, B.R.; LEES, G.E. Effects of serial ultrasound-guieded renal biopsies on kidneys of healthy adolescent dogs. Veterinary Radiology \& Ultrasound, Raleigh, v. 45, n. 1, p. 62-69, 2004.

GUILLOT, M., DANJOU, M.A., ALEXANDER, K., BEDARD, C., DESNOYERS, M., BEAUREGARD, G., CASTILLO, J.R.E. Can sonographic findings predict the results of liver aspirates in dogs with suspected liver disease? Veterinary Radiology \& Ultrasound, Raleigh, v. 50, n. 5, p. 513-518, 2009.

HEDLUND, C.S. Cirurgia do sistema reprodutor e genital. In: FOSSUM,T.W. Cirurgia de pequenos animais.1 ed, Roca, São Paulo, p.611-622, 2002.

IVERSEN, P., BRUN, C. Aspiration biopsy of the kidney. American Journal of Medicine, Nova York, v.11, p. 324-330, 1951.

JOHNSTON, S.D.; KAMOLPATANA, K.; ROOT-KUSTRITZ, M.V.; JOHNSTON,G.R. Prostatic disorders in dog. Animal Reproduction Science, Amsterdam, v. 60, p. 405-415, 2000.

LeBLANC, C.; HEAD, L.L.; FRY, M.M. Comparison of aspiration techniques for obtaining cytologic samples from the canine and feline spleen. Veterinary Clinical Pathology, Santa Barbara, v. 38, n. 2, p. 242-246, 2009.

LIEVE, M.J.H.; DeRYCKE, D.V.M.; HENRI, J.J.; SIMOEN, D.V.M. Ultrasoundguieded tissue-core biopsy of liver, spleen and kidney in normal dogs. Ultrasound, Philadelphia, v. 40, n. 3, p. 294-299, 1999.

LIEVE, M.J.H.; RYCKE, D.V.M.; HENRI, J.J.; BREE, D.V.M.; PAUL, J.M.; SIMOENS, D.V.M. Ultrasound-guided tissue core biopsy of liver, spleen and kidney in normal dogs. Veterinary Radiology \& Ultrasound, Raleigh, v.40, n. 3, p. 249-299, 1999.

MELCHERT, A.; MOUTINHO, F.Q.; MAMPRIM, M.J.; SANTOS, F.A.M. Biopsia renal percutânea monitorizada por ultrassonografia em cães. Ciência Animal Brasileira, Goiânia, v. 11, n. 2, p. 447-453, 2010. 
MENARD, M.; PAPAGEORGES, M. Ultrasound corner: technique for ultrasoundguided fine needle biopsies. Veterinary Radiology \& Ultrasound, Raleigh, v. 36, p. 137-138, 1995.

MIX, K.; JONE, C. Diagnosing acute pancreatitis. Compendium, Housten, v.4, p. 226-232, 2006.

NYLAND, T.G; MATTON, J.S. Biopsia guiada por ultrassom. In: NYLAND, T.G. \& MATTOON, J.S. Ultra-som diagnóstico em pequenos animais. 2 ed. São Paulo: Roca, p. 33 - 52.2005.

POWE, J.R.; CANFIELD, P.J.; MARTIN, P.A. Evaluation of the cytologic diagnosis of canine prostatic disorders. Veterinary clinical pathology. v.33, n.3, p.150-154, 2004.

ROTHUIZEN, J. Deseases of liver and biliary tract. In: DUN, J. Textbook of small animal medicine. London: Saunders, p. 448-497.1999.

ROTHUIZEN, J.; TWEDT, D.C. Liver biopsy techniques. Veterinary Clinical Small Animal, v. 39, p. 469-480, 2010.

SANTANA, C.V. Estudo histológico e histoquímico de próstata de cães em diferentes idades. Dissertação de mestrado. Belo Horizonte, Universidade Federal de Minas Gerais, 64p, 2006.

SODERSTROM, N. Anatomy and histology of the spleen. In: Aspiration biopsy cytology. Monographs in clinical cytology of infradiaphagmatic organs, v. 7, part. 2, S Karger, Basel, p. 224-247, 1979.

SOUZA, F.F.; TONIOLLO, G.H. Avaliação da glândula prostática canina. Revista brasileira de reprodução animal. v.23, n.3, p.243-244, 1999.

THIBAUT, J.; SANTANDER, J.; MIERES, M.; Comparative study of the canine prostate using transrectal and transabdominal ultrasonographic techniques. Archivos de medicina, Valdivia, Suplemento 2, p. 61-66, 2009.

VADEN, S.L.; LEVINE, J.F.; LEES, G.E.; GROMAN, P.R.; GRAUER, G.F.; FORRESTER, S.D. Renal biopsy: a retrospective study of methods and complications in 283 dogs and 65 cats. Journal of Veterinary Internal Medicine, Lawrence, v. 19, n. 6, p. 781-794, 2005.

VASAJEE, S.C., BUBENIK, L.J., HOSGOOD, G. Evalution of hemorrhagic, same size and collateral damage for five hepatic biopsy methods in dogs. Veterinary Surgical, v. 35, n. 1, p. 86-93, 2006.

VIGNOLI, M; SAUNDERS, JH. Image-guieded interventional procedures in dog and cat. The Veterinary Journal, London, 2010.

WANG, KY., PANCIERA, D.L., RUKIVAT, R.K. Accuracy of ultrasound-guieded fine 
needle aspiration of the liver and cytologic findings in dogs and cats: 97 cases (1990-2000). Journal American Hospital Association, v.224, p. 75-78, 2004.

WHITE, R.A.S. Prostatic surgery in dog. Clinical techniques in small animal practice, Philadelphia, v.15, n.1, p. 46-41, 2000.

WILLARD, M. Fine-needle aspirate cytology suggesting hepatic lipidosis in four cats with infiltrative hepatic disease. Journal Feline Medicine Surgery, v. 1, n. 4, p. 215-220, 1999.

WINTER,T.C.; LEE, J., HINSHAW, J.L. Ultrasosound-guided biopsies in abdômen and pélvis. Ultrasound Quartely, v.24, p. 45-68, 2008.

ZAJDELA, A.; ZILHARDT, P.; VOLLEMONT, N. Cytological diagnoses by fine needle sampling with aspiration. Cancer, v. 59, p. 1021-1205, 1987.

ZATELLI, A.; DIPPOLITO, P.; ZINI, E. Comparison of glomerular number and specimen length obtained from 100 dogs via echo -assisted renal biopsy using two different needles. Radiology \& Ultrasound, Raleigh, v. 46, n. 5, p. 434-436, 2005. 